\title{
Inhibin $\beta B$ expression in murine adipose tissue and its regulation by leptin, insulin and dexamethasone
}

\author{
N Hoggard, M Cruickshank, K M Moar, P Barrett, S Bashir and J D B Miller ${ }^{1}$ \\ Rowett Institute of Nutrition and Health, Aberdeen Centre for Energy Regulation and Obesity (ACERO), University of Aberdeen, Bucksburn, Aberdeen, Scotland AB21 9SB, UK \\ 'Department of Surgery, Dr Gray's Hospital, Elgin, UK \\ (Correspondence should be addressed to N Hoggard; Email: nh@ rowett.ac.uk)
}

\begin{abstract}
Inhibin $\beta B$ (INHBB; coding for the activin $\beta B$ subunit) has previously been identified in both human and rodent adipose tissue and using Taqman real-time PCR with specific primers we confirm the expression of INHBB mRNA in rodent adipose tissue. Expression of INHBB in murine epididymal adipose tissue was higher than in any of the other tissues studied and appears to be regulated by changes in energy balance and leptin. It was increased fourfold in the epididymal fat depot of $o b / o b$ mice compared with the same fat depot in lean mice. The i.p. administration of leptin in obese $o b / o b$ mice decreases the expression of INHBB. In human adipose tissue, INHBB is reduced by weight loss. In keeping with this, we demonstrate that INHBB expression in murine adipose tissue is decreased in fasting and increased upon refeeding. We show that INHBB is expressed in both the mature adipocyte and the stromal vascular fraction of adipose tissue. INHBB increases with the differentiation of pre-adipocytes into mature adipocytes in the 3T3-L1 cell line. In differentiated 3T3-L1 adipocytes, where receptors to activin have been previously reported, insulin increases the expression of INHBB, while dexamethasone decreases the expression of INHBB when compared with untreated control cells. Taken together, these results suggest that the regulation of INHBB expression in adipose tissue may play a physiological role in energy balance or the insulin insensitivity associated with obesity.
\end{abstract}

Journal of Molecular Endocrinology (2009) 43, 171-177

\section{Introduction}

Activins are multifunctional growth factors that are functionally and structurally distinct members of the transforming growth factor (TGF)- $\beta$ superfamily of proteins (Chang et al. 2002). Although the majority of studies have focused on activin's role in reproduction and development, it is clear that activins also have a role locally in the cellular development and growth of different tissues (Muttukrishna et al. 2004, Rodgarkia-Dara et al. 2006, Werner \& Alzheimer 2006, Maeshima et al. 2008). Activins are synthesised as homo- or heterodimers of two highly related disulphide-linked inhibin $\beta$ subunits (inhibin $\beta A$ (INBBA) and inhibin $\beta B$ (INHBB)), which can result in three molecular species activin $\mathrm{A}$, activin $\mathrm{AB}$ and activin $\mathrm{B}$ (Rodgarkia-Dara et al. 2006). Thus, the INHBB subunit can form activin B together with another $\beta B$ subunit $(\beta B-\beta B)$ or activin $A B$ together with the $\beta A$ subunit $(\beta A-\beta B)$. Two other subunits $\mathrm{BC}$ and $\mathrm{BE}$ are also members of the activin subgroup but research has focused more on the widely expressed $\beta \mathrm{A}$ and $\beta \mathrm{B}$ subunits (Rodgarkia-Dara et al. 2006). These TGF- $\beta$ families of proteins, acting as paracrine, autocrine or endocrine factors, have a wide range of functions essential in normal physiological and developmental processes.
Recently, INHBB was identified in human white adipose tissue, while INBBA, INBBC and INBBE were expressed at very low levels suggesting that INHBB is the predominant activin in human adipose tissue (Sjoholm et al. 2006). Thus, these data suggest that only the activin $\mathrm{B}$ dimer is produced in human adipose tissue as the dimerisation of activin subunits occurs within the cell. This is in contrast to rodent adipose tissue, where both INHBA and INHBB mRNAs are expressed indicating a difference between the species (Vejda et al. 2002). Type I and Type II receptors to activin are also expressed in human and rodent adipose tissue suggesting a possible autocrine or paracrine effect of activin (Rodgarkia-Dara et al. 2006, Sjoholm et al. 2006). Activin B has been shown to signal via an additional Type 1 receptor ALK7 when compared with activin $\mathrm{A}$, which suggests that these activins may have different functions (Thompson et al. 2004, RodgarkiaDara et al. 2006). Furthermore, the ALK7 receptor is highly expressed in human adipose tissue suggesting that activin B may have local effects in the adipose tissue (Carlsson et al. 2009).

INHBB coding for the activin $\beta \mathrm{B}$ is highly expressed in human adipocytes and the expression is decreased with diet-induced weight loss, correlating with serum levels of fasting insulin (Sjoholm et al. 2006, 
Carlsson et al. 2009). To investigate the significance of this, we further investigated the changes in INHBB expression in diabetic obese $o b / o b$ mice, $24 \mathrm{~h}$ fasted C57BL6 mice and in the 3T3-L1 adipocyte cell line.

\section{Methods}

\section{Animals}

Wild-type and obese $o b / o b$ male mice on the C57BL6 background (all $\sim 11$ weeks old) were purchased from Harlan UK Ltd (Bicester, Oxon, UK). Animals were maintained on a 12:12-h photoperiod with lights on at $0800 \mathrm{~h}$. Room temperature was controlled at $20^{\circ} \mathrm{C}$ $\left( \pm 1^{\circ} \mathrm{C}\right)$ and humidity was regulated to be $<70 \%$. Food (Biosure CRM pelleted chow: Special Diets Services, Witham, Essex, UK) and water were available ad libitum unless stated. The CRM pelleted chow has an estimated metabolisable energy of $12-13 \mathrm{MJ} / \mathrm{kg}$, partitioned as Atwater fuel energy, protein $22 \%$, fat $9 \%$ and carbohydrate $69 \%$.

All procedures were licensed under the UK Animals (Scientific Procedures) Act of 1986 and received ethical approval from the University of Aberdeen Rowett Institute of Nutrition and Health Ethical Review Committee.

\section{I.p. leptin administration}

A total of 10 obese $(o b / o b)$ mice were used to determine the effect of the i.p. administration of leptin on the expression of INHBB in adipose tissue. Half the mice $(n=5)$, with ad libitum access to food and water, were injected i.p. with leptin $(2 \mathrm{mg} / \mathrm{kg}$ body weight in saline) in the middle of the light phase. The other half $(n=5)$ received saline $(100 \mu \mathrm{l})$ only. After $4 \mathrm{~h}$, the mice were killed by cervical dislocation and tissues collected for analysis. All murine tissues described were carefully dissected and then frozen immediately in liquid nitrogen and stored at $-80{ }^{\circ} \mathrm{C}$ until extraction of RNA.

\section{Fasting}

Food was withdrawn for $24 \mathrm{~h}$ from randomly selected lean C57BL6 mice soon after the onset of the light cycle, whereas control animals were provided with ad libitum access to chow. Some individuals from the fasted group were then permitted a $12 \mathrm{~h}$ ad libitum refeeding period. Animals were killed after $24 \mathrm{~h}$ (control and fasted groups) or $36 \mathrm{~h}$ (refed group; $n=8$ per group). The adipose tissue was carefully dissected and then frozen immediately in liquid nitrogen and stored at $-80^{\circ} \mathrm{C}$ until extraction of RNA.

\section{Mature adipocyte isolation}

Mature adipocytes were isolated from the murine epididymal fat depot of 11 weeks old C57BL6 male mice. In brief, following dissection, the WAT samples were placed in 1\% Albumin buffer (1\% BSA in HEPES buffer). Following removal of blood vessels, the tissue was diced and transferred to collagenase buffer $(1 \mathrm{mg} / \mathrm{ml}$ collagenase type II in HEPES buffer, $\mathrm{pH}$ $7 \cdot 4$ ) and placed in a shaking incubator at $37^{\circ} \mathrm{C}$ for $1 \mathrm{~h}$, or until digestion was complete. The digested tissue was passed through a $250 \mu \mathrm{m}$ mesh and centrifuged at $200 \mathrm{~g}$ for $10 \mathrm{~min}$ to pellet the stromal vascular fraction (SVF). The mature fat cells floating at the top were then transferred to fresh tubes and rinsed thrice with HEPES buffer and centrifuged at $200 \mathrm{~g}$ for $5 \mathrm{~min}$. Finally, excess buffer was removed and Tri-pure isolation reagent (Roche Diagnostics Ltd) was added. The stromal vascular pellet was incubated for $10 \mathrm{~min}$ in erythrocyte lysis buffer $\left(154 \mathrm{mM} \mathrm{NH} \mathrm{NH}_{4} \mathrm{Cl}, 5.7 \mathrm{mM} \mathrm{K} \mathrm{K}_{2} \mathrm{HPO}_{4}\right.$ and $0 \cdot 1 \mathrm{mM}$ EDTA, $\mathrm{pH} 7 \cdot 3$ ). The suspension was then centrifuged at $200 \mathrm{~g}$ for $10 \mathrm{~min}$ and the pellet was resuspended in Tri-pure isolation reagent (Roche Diagnostics Ltd).

\section{T3-L1 cell culture}

3T3-L1 cells were obtained from the LGC Promochem (Teddington, Middlesex, UK) and cultured at $37^{\circ} \mathrm{C}$ in a humidified atmosphere of $5 \% \mathrm{CO}_{2}$ and $95 \%$ air. The cells were maintained in a culture medium containing the following: DMEM (Invitrogen) with $25 \mathrm{mM}$ glucose, $1 \mathrm{mM}$ pyruvate, $4.02 \mathrm{mM}$ L-alanyl-L-glutamine and $10 \%$ FCS (Sigma). Differentiation was initiated $24 \mathrm{~h}$ after confluence by incubation for 2 days in a culture medium containing $0.25 \mu \mathrm{M}$ dexamethasone (Dex), $0.5 \mathrm{mM}$ 3-isobutyl-1-methyl-xanthine and $5 \mu \mathrm{g} / \mathrm{ml}$ insulin (Sigma). This was followed by maintenance in feeding medium (renewed every $2 / 3$ days) consisting of culture medium containing $5 \mu \mathrm{g} / \mathrm{ml}$ insulin. Cells were fully differentiated by day 11 with over $90 \%$ of the cells containing lipid droplets. The cells were maintained for up to 11 days after the induction of differentiation and sampled every 2-3 days. In some experiments, fully differentiated adipocytes at day 11 were incubated for a further $24 \mathrm{~h}$ with insulin $(1$ and $10 \mu \mathrm{M})$, leptin $(10,100$ and $1000 \mathrm{nM}$ ), lipopolysaccharide (LPS; 25 and $75 \mathrm{ng} / \mathrm{ml}$ ) or Dex (2 and $20 \mathrm{nM}$ ). All reagents were purchased from Sigma. Cells were harvested and RNA was extracted as described below for PCR analysis.

\section{Real-time quantitative PCR (Taqman system)}

RNA was extracted using the Tri-pure isolation reagent, for DNA-free RNA, following the manufacturer's instructions (Roche Diagnostics Ltd). RNA was 
accurately quantified on the Agilent 2100 Bioanalyser (Agilent Technologies, South Queensferry, West Lothian, UK). This also shows the quality of the RNA extracted from the tissues. Only RNA showing no degradation was processed further. Reverse transcription was carried out on 3-5 $\mathrm{gg}$ of RNA using the Superscript first strand synthesis system (Invitrogen Cat No: 12371-019) according to the manufacturer's instructions. The cDNA was amplified by PCR using rodent-specific (Applied Biosystems cat number $\mathrm{Mm}$ 01286587_m1) primers for the INHBB gene or for the leptin gene (Applied Biosystems, Warrington, Cheshire, UK, cat number Mm00434759_m1).

PCR was performed on an Applied Biosystems ABI Prism 7700 sequence detection system (Perkin-Elmer Applied Biosystems, Inc., Foster City, CA, USA). Commercial reagents (TaqMan PCR Reagent Kit, Perkin-Elmer) and conditions were employed according to the manufacturer's protocol. cDNA $(1 \mu \mathrm{l}$; reverse transcription mixture) and oligonucleotides with a final concentration of $300 \mathrm{nmol} / 1$ primers and $200 \mathrm{nmol} / 1$ TaqMan hybridisation probe were added to $10 \mu \mathrm{l}$ reaction mix.

PCR was performed under the following conditions: step $1,95{ }^{\circ} \mathrm{C}(20 \mathrm{~s})$ for 1 cycle; step $2,95^{\circ} \mathrm{C}(3 \mathrm{~s}) ; 60^{\circ} \mathrm{C}$ $(30 \mathrm{~s})$ for 40 cycles. All samples were run in triplicate and were all within the standard curve.

A serial dilution of known copy numbers of a PCR product served as reference (standard curve) providing a relative quantification of the unknown samples. Target gene expression was related to the housekeeping genes $\beta$-actin (Primers obtained from Applied Biosystems cat number rodent Mm00607939_s1) and $\beta-2$ microglobulin (B2M; Primers obtained from Applied Biosystems cat number rodent Mm00437762_s1), following the manufacturer's instructions. All of the primers and probes were purchased from Applied Biosystems as TaqMan Gene Expression Assays, which have been designed and validated by Applied Biosystems. Further details of all the primers are available at the Applied Biosystems website under the catalogue numbers provided.

Values were standardised to $\beta$-actin and expressed as a percentage of the control. Similar data were obtained when the values were standardised to B2M (data not shown). Suitable controls were carried out to eliminate any potential for spurious amplification from contaminating genomic DNA.

\section{Statistical analysis}

Comparisons between groups were made using unpaired Student's $t$-tests. Results were considered statistically significant if the $P \leq 0 \cdot 05$. Where appropriate the data were also analysed by one- or two-way ANOVA using GenStat version 11.

\section{Results}

\section{Expression of INHBB mRNA in murine tissues}

To determine the level of expression of INHBB mRNA in murine tissues we carried out real-time PCR with the Taqman system on a range of tissues dissected from lean C57BL6 mice that had ad libitum access to food and water. We also compared the expression in the murine subcutaneous, epididymal and perirenal adipose tissue depots (Fig. 1).

INHBB expression in murine epididymal adipose tissue was at least twofold higher than the other tissues studied including perirenal and subcutaneous adipose tissue, spleen, Bat (brown adipose tissue), kidney, liver, heart, testis and lung $(P \leq 0 \cdot 01)$. Excluding the epididymal adipose tissue, INHBB was expressed at higher levels in the testis of these mice compared with other tissues $(P \leq 0 \cdot 05)$ in keeping with previous reports (Vejda et al. 2002). Owing to the high level of INHBB mRNA expression in the murine epididymal adipose tissue, data are presented mainly for this fat depot in subsequent experiments.

\section{Expression of INHBB mRNA in the adipose tissue of obese ob/ob compared with C57BL6 lean mice: effect of i.p. administration of leptin to obese ob/ob mice compared with saline-treated controls}

To determine whether INHBB mRNA in adipose tissue is regulated by changes in leptin, we carried out realtime PCR in the obese diabetic $o b / o b$ mouse using the Taqman assay with primers specific to INHBB (Fig. 2).

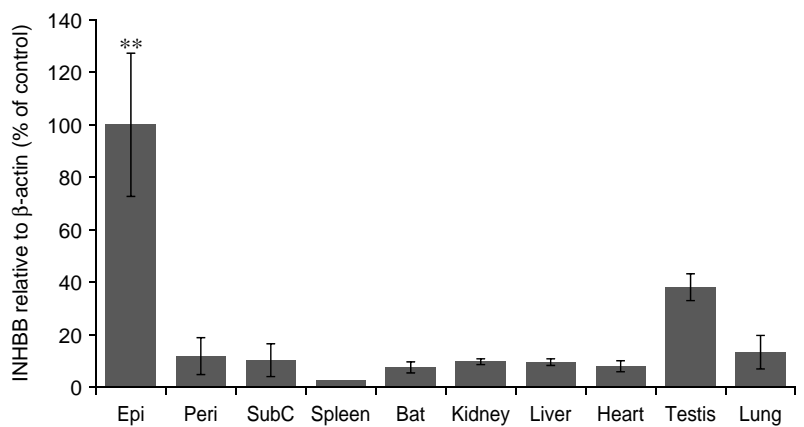

Figure 1 Expression of inhibin $\beta B$ (INHBB) mRNA is higher in murine epididymal adipose tissue (Epi) when compared with perirenal adipose tissue (Peri), subcutaneous (SubC) adipose tissue, spleen, brown adipose tissue (Bat), kidney, liver, heart, testis ( ${ }^{\star \star} P \leq 0.01$ ) and lung dissected from lean C57BL6 mice. INHBB mRNA was determined by qRT-PCR using the Taqman assay and primers specific for murine INHBB. Results are expressed as a percentage of the control, which in this case is taken as expression in the lean rodent epididymal fat depot (the highest expression). $n=3$ for each point \pm S.E.M. related to the expression of the housekeeping gene $\beta$-actin. This was replicated in independent amplifications. 


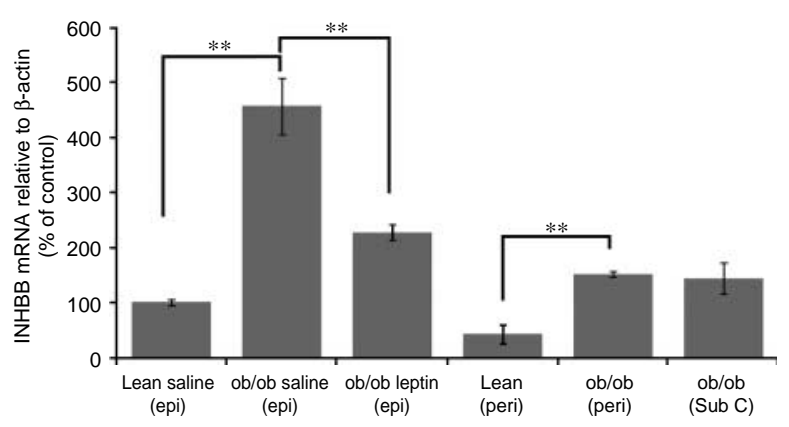

Figure 2 INHBB mRNA is higher in the epididymal and perirenal adipose tissue depot of ob/ob mice $(P \leq 0.05)$ compared with lean C57BL6 mice on the same background. The administration of leptin i.p. at $2 \mathrm{mg} / \mathrm{kg}$ body weight to ob/ob mice decreases INHBB mRNA in the adipose tissue compared with saline treated $o b / o b$ controls after $4 \mathrm{~h}(P \leq 0.05)$. INHBB mRNA is expressed at a lower level in the perirenal and subcutaneous depot when compared with the epididymal adipose tissue depot of $o b / o b$ mice $(P \leq 0.05)$. INHBB mRNA was determined by qRT-PCR using the Taqman assay and primers specific for murine INHBB. Results are expressed as a percentage of the control which in this case is taken as the expression in the epididymal fat depot of the lean C57BL6 saline treated mice, $n=5$ for each point \pm s.E.M. related to the expression of the housekeeping gene $\beta$-actin. $P$ values ${ }^{* *} P \leq 0 \cdot 01$. This was replicated in independent amplifications.

INHBB is increased fourfold in the epididymal fat depot of the $o b / o b$ mouse compared with the same fat depot in lean mice on the same C57BL6 background $(P \leq 0 \cdot 01)$. In addition, it is decreased with the i.p. administration of leptin $(2 \mathrm{mg} / \mathrm{kg}$ body weight $)$ in obese $o b / o b$ mice after $4 \mathrm{~h}(P \leq 0 \cdot 01)$ compared with saline-treated obese $o b / o b$ mice. A similar increase in INHBB gene expression was observed in the perirenal fat depot in $o b / o b$ mice when compared with the same fat depot in lean mice $(P \leq 0 \cdot 01)$. INHBB gene expression in the perirenal adipose tissue depot was comparable with the subcutaneous adipose tissue depot in the $o b / o b$ mice. Using two-way ANOVA, there is a significant effect of both leptin $(P=0 \cdot 001)$ and adipose tissue depot $(P=0 \cdot 01)$ as well as an interaction of the two $(P=0 \cdot 04)$ on INHBB gene expression.

\section{Expression of INHBB mRNA in murine adipose tissue decreased with fasting in the C57BL6 mouse}

To determine whether adipose tissue INHBB mRNA is altered by changes in the feeding status, we fasted C57BL6 lean mice for $24 \mathrm{~h}$. Some individuals from the fasted group were then permitted a $12 \mathrm{~h}$ ad libitum refeeding period. We measured INHBB mRNA by the Taqman assay in epididymal adipose tissue (Fig. 3). INHBB mRNA is decreased in the fasted C57BL6 lean mice relative to the fed controls $(P \leq 0 \cdot 01)$. INHBB mRNA increased in fasted C57BL6 lean mice that were subsequently refed for a further $12 \mathrm{~h}(P \leq 0 \cdot 01)$. Using one-way ANOVA, there is a significant effect of fasting on INHBB gene expression $(P=0 \cdot 027)$.

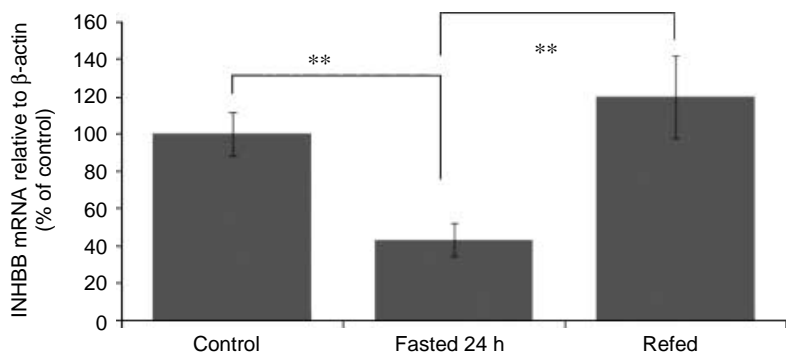

Figure 3 INHBB mRNA is lower in the epididymal adipose tissue depot of $24 \mathrm{~h}$ fasted C57BL6 mice $(P \leq 0.01)$ compared with fed controls. Refeeding the C57BL6-fasted mice for $24 \mathrm{~h}$ increased INHBB mRNA in the epididymal adipose tissue depot to that observed in the fed controls $(P \leq 0 \cdot 01)$. INHBB mRNA was determined by qRT-PCR using the Taqman assay and primers specific for murine INHBB. Results are expressed as a percentage of the control, which in this case is taken as the expression in the fat depot of the fed control mice, $n=8$ for each point \pm S.E.M. related to the expression of the housekeeping gene $\beta$-actin. $P$ values ${ }^{* \star} P \leq 0 \cdot 01$. This was replicated in independent amplifications.

\section{INHBB mRNA is expressed in mature adipocytes and the SVF}

Adipose tissue is heterogeneous at the cellular level with mature adipocytes comprising no more than $50 \%$ of the total cell content. To establish the cellular localisation of INHBB in WAT, epididymal fat from C57BL6 mice was fractionated by collagenase digestion into stromal vascular and mature adipocyte components. INHBB mRNA was measured using the Taqman assay and products for INHBB mRNA were observed in both the adipocyte and SVFs (Fig. 4). As expected, leptin mRNA expression was mainly expressed in the mature adipocyte fraction.

\section{INHBB mRNA is expressed in the murine adipocyte 3T3-L1 cell line}

The developmental expression of INHBB mRNA during the course of differentiation from pre-adipocytes into mature adipocytes was determined using the Taqman assay in the 3T3-L1 adipocyte cell line (Fig. 5).

INHBB mRNA can be readily detected in preadipocytes and differentiated mature adipocytes. INHBB mRNA remained unchanged during the first 2 days of culture in medium containing $0.25 \mu \mathrm{M}$ Dex, $0.5 \mathrm{mM}$ 3-isobutyl-1-methyl-xanthine and $5 \mu \mathrm{g} / \mathrm{ml}$ insulin. Thereafter, INHBB mRNA levels gradually increased with increasing differentiation of the preadipocytes into mature adipocytes $(P \leq 0 \cdot 001)$. As expected, leptin mRNA levels also increased with increasing differentiation of the pre-adipocytes into mature adipocytes as previously reported (Rentsch \& Chiesi 1996). Differentiation of the 3T3-L1 cells from 


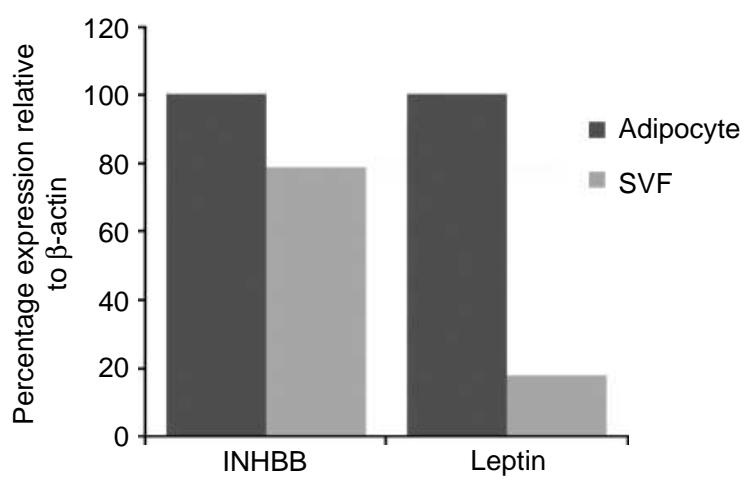

Figure 4 First strand cDNA synthesis and subsequent qRT-PCR analysis were performed on RNA isolated from mature adipocyte and stromal vascular fractions separated by collagenase digestion from epididymal fat dissected from C57BL6 mice. INHBB and leptin mRNA were determined by qRT-PCR using the Taqman assay and primers specific for murine INHBB and leptin respectively. Results are expressed relative to the expression of the housekeeping gene, $\beta$-actin and as a percentage of the expression in the mature adipocyte fraction. SVF, stromal vascular fraction; adipocyte, mature adipocytes.

pre-adipocytes into mature adipocytes was also evident from the accumulation of intracellular lipid droplets for which the differentiation rate was $>90 \%$.

\section{Regulation of INHBB mRNA expression in differentiated murine adipocyte 3T3-L1 cells}

To investigate the regulation of INHBB gene expression in vitro, we incubated differentiated day 11 murine adipocyte 3T3-L1 cells with insulin $(1$ or $10 \mu \mathrm{M})$, leptin $(10,100$ or $1000 \mathrm{nM})$, LPS $(25$ or $75 \mathrm{ng} / \mathrm{ml})$ or Dex ( 2 or $20 \mathrm{nM}$ ) for $24 \mathrm{~h}$ and compared with control untreated cells (Fig. 6).

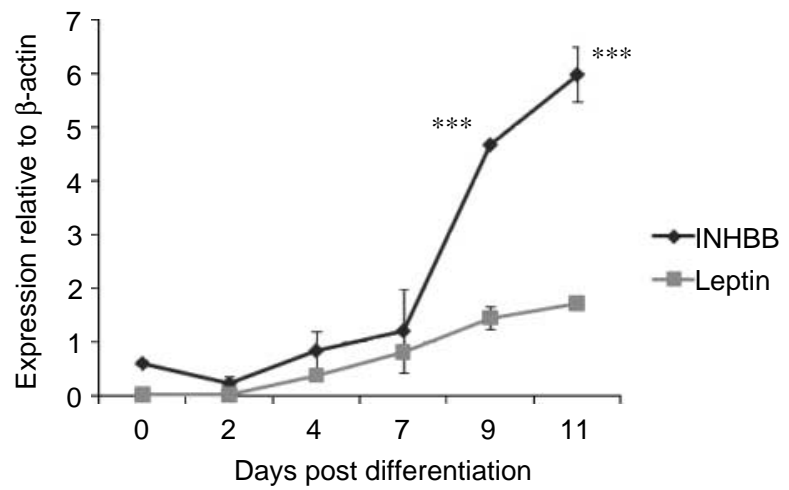

Figure 5 INHBB and leptin gene expression in 3T3-L1 cells before and after differentiation into mature adipocytes. Differentiation was initiated on day 0 . INHBB and leptin mRNA were determined by qRT-PCR using the Taqman assay and primers specific for murine INHBB and leptin respectively. Results are expressed relative to the expression of the housekeeping gene, $\beta$-actin. $n=3$ for each point \pm S.E.M. This was replicated in independent amplifications. $P$ values ${ }^{\star * \star} P \leq 0.001$.

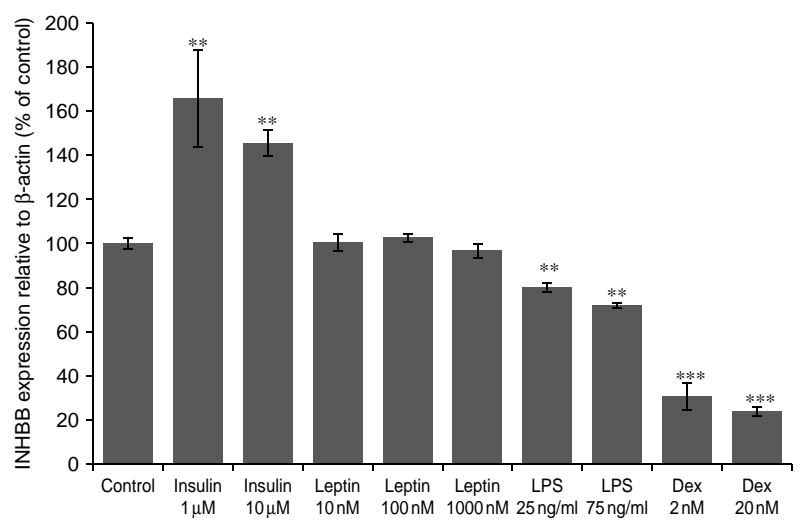

Figure 6 The addition of insulin ( 1 and $10 \mu \mathrm{M})$ to primary cultures of differentiated adipocytes for $24 \mathrm{~h}$ significantly stimulates INHBB mRNA expression compared with untreated control cells $(P \leq 0.05)$, while lipopolysaccaride (LPS; 25 and $75 \mathrm{ng} / \mathrm{ml}$; $P \leq 0.05)$ and dexamethasone (Dex; 2 and $20 \mathrm{nM} ; P \leq 0.001)$ inhibits INHBB mRNA expression. No significant effect of leptin $(10,100$ or $1000 \mathrm{nM})$ was observed on INHBB expression. INHBB mRNA was determined by qRT-PCR using the Taqman assay and primers specific for murine INHBB. Results are expressed as a percentage of the control untreated differentiated cells. $n=3$ for each point \pm S.E.M. related to the expression of the housekeeping gene, $\beta$-actin. $P$ values ${ }^{* \star} P \leq 0.01,{ }^{\star * \star} P \leq 0.001$. This was replicated in independent amplifications.

Insulin $(1$ and $10 \mu \mathrm{M})$ increased INHBB mRNA expression by $\sim 50 \%(P \leq 0 \cdot 01)$ when compared with the untreated control differentiated murine adipocytes. INHBB mRNA expression was decreased by $\sim 25 \%$ with LPS (25 and $75 \mathrm{ng} / \mathrm{ml} ; P \leq 0 \cdot 01$ ) and $\sim 70 \%$ with Dex (2 and $20 \mathrm{nM} ; P \leq 0 \cdot 001$; Fig. 6 ). The addition of leptin $(10,100$ or $1000 \mathrm{nM})$ had no effect on INHBB mRNA expression measured using the Taqman assay (Fig. 6). This is in contrast to the in vivo studies showing a decrease in INHBB mRNA in adipose tissue in response to i.p. administration of leptin to obese C57BL6 mice (Fig. 2). It is also in contrast to the decrease of INHBB we observed in fasting (Fig. 3) which would also decrease leptin levels, suggesting that leptin has an indirect effect on INHBB mRNA expression (Ueno $\mathrm{et}$ al. 2007). Using one-way ANOVA, there is a significant effect of treatment on INHBB gene expression $(P<0 \cdot 001)$.

\section{Discussion}

A previous study by Sjoholm et al. (2006) demonstrates the expression of INHBB in the adipose tissue of obese human volunteers. When placed on a weight loss study, INHBB expression decreased in the subcutaneous adipose tissue of these volunteers and this decrease positively correlated with the fasting levels of insulin. These data lead to the hypothesis that INHBB, which 
can form activin $\mathrm{B} / \mathrm{AB}$ protein derived from adipose tissue, may be regulated by insulin or could regulate insulin secretion from the pancreatic islets. To begin to address this hypothesis, we investigated the expression of INHBB mRNA from adipose tissue in $o b / o b$ mice, fasted mice and in differentiated 3T3-L1 cells.

We show in this study that INHBB mRNA in C57BL6 mice is expressed at a high level in the epididymal adipose tissue depot compared with the perirenal and subcutaneous adipose tissue depot as well as a range of other tissues including the testis, a tissue where high expression has previously been reported (Vejda et al. 2002). Real-time PCR analysis, of two adipose tissue depots, demonstrates that INHBB is increased in the adipose tissue of obese diabetic $o b / o b$ mice compared with lean mice on the same C57BL6 background. Leptin administration to rodents is known to improve insulin sensitivity by reducing intracellular lipid levels in skeletal muscle, liver and pancreatic $\beta$-cells (Minokoshi et al. 2002). The administration of leptin peripherally to the obese (leptin-deficient) $o b / o b$ mouse in this study caused a decrease in INHBB mRNA expression in the adipose tissue. This association between leptin levels and expression of INHBB mRNA in adipose tissue in vivo contrasts with our in vitro findings, which show no effect of leptin on INHBB mRNA in differentiated 3T3-L1 adipocytes. This suggests that the effect of leptin on the adipose tissue expression of INHBB in vivo occurs indirectly.

It may be the increase in plasma insulin associated with obesity in diabetic $o b / o b$ mice compared with lean mice causes the increase in INHBB mRNA that we observe in the adipose tissue depots of these mice (Kulkarni et al. 1997). In keeping with this, we show that insulin increases INHBB expression in differentiated 3T3-L1 adipocytes. Additionally, if the increase in INHBB mRNA in the adipose tissue reflects an increase in plasma activins, this may be partly responsible for the observed increase in plasma insulin in obese $o b / o b$ mice compared with lean mice. Previous studies have shown that activins composed of the INHBB subunit cause an increase in insulin with specific activin receptors being present on pancreatic islet cells (Tsuchida et al. 2004). It should be noted that follistatin and other carrier proteins are known to bind activin in the blood abolishing receptor binding and thus limiting the bioavailability of activin. However, the affinity of follistatin for activin B composed of INHBB subunits is reported to be $\sim 10$-fold lower than that for activin A (Rodgarkia-Dara et al. 2006). Similarly, the administration of leptin to $o b / o b$ mice may indirectly, through changes in plasma insulin, cause the observed decrease in the expression of INHBB mRNA in adipose tissue (Kulkarni et al. 1997). By reducing the insulin stimulus, we would expect the levels of INHBB in the adipose tissue to decrease, given that we show insulin increases
INHBB in the 3T3-L1 mature adipocytes. It would be interesting to measure serum levels of activin B were a specific assay readily available.

We also show that INHBB expression in rodent adipose tissue is decreased in fasted C57BL6 lean mice relative to the fed controls. Furthermore, we show that INHBB mRNA is increased in fasted C57BL6 lean mice that were subsequently refed. Given that insulin levels fall with fasting and would be restored by refeeding, this gives additional support to the hypothesis that INHBB is associated with changes in insulin (Ueno et al. 2007).

The presence of INHBB receptors including the ALK7 receptor in the adipose tissue suggests that the INHBB expressed in adipose tissue giving rise to activin may have important autocrine or paracrine actions (Rodgarkia-Dara et al. 2006, Carlsson et al. 2009). In keeping with this, activin $\mathrm{A}$, a homodimer of the activin $\beta A$ subunit which signals via the same receptors as activin $\mathrm{B} / \mathrm{AB}$, has been shown to inhibit differentiation of adipocyte 3T3-L1 cells into mature adipocytes (Hirai et al. 2005). Using 3T3-L1 cells, the present study shows that the expression of INHBB mRNA is greater in differentiated mature adipocytes than in preadipocytes. Although significant levels of INHBB mRNA are detected in the mature adipocytes and in adipose tissue itself, INHBB mRNA is also detected at approximately the same levels in the SVF. This could reflect an expression in any component of that fraction, including fibroblasts, vascular endothelial cells and immune cells (including mast cells and macrophages), in addition to immature adipocytes. This suggests that there might be an interaction between the cells of the SVF and the mature adipocytes, which express receptors to INHBB. It is interesting to note, therefore, that INHBB expression is decreased by LPS, which stimulates an inflammatory response. This may indicate a role for INHBB in the obesity-associated inflammatory response (Trayhurn \& Wood 2004).

Activin subunits along with their respective receptors are expressed in the rodent brain. Thus, in addition to any local effect that activins have, they may also have an endocrine action in the brain with central effects on whole body metabolism (Meunier et al. 1988, Sawchenko et al. 1988, Cameron et al. 1994). Activin A plays a modulatory role in the function of the hypothalamic-pituitary-adrenal axis including an increased release of corticotropin-releasing hormone (Plotsky et al. 1991). With respect to this, it is interesting to note that we show that Dex causes a $70 \%$ decrease in INHBB mRNA expression in differentiated 3T3-L1 adipocytes.

Activin and inhibin have also been shown to be involved in the central regulation of nutrient and fluid balance (Kubota et al. 2003). Mice homozygous for the inhiba-null allele show disruption of whisker, palate and tooth development leading to neonatal lethality, 
whereas by contrast, mice homozygous for the inhibanull allele are viable, fertile and have eye defects. Interestingly, replacement of the inhiba-null alleles by the inhibb allele has been shown to give rise to cachexia in these recombinant mice and also effects adipose tissue mass (Brown et al. 2000). This paper also provides support for a role of INHBB in relation to food intake, in that INHBB mRNA expression increases with obesity in the $o b / o b$ mouse and decreases with fasting. Additional studies are needed to clarify the effects of obesity and type 2 diabetes on INHBB expression.

In conclusion, INHBB is expressed in mature adipocytes and in adipocytes differentiated in primary culture, as well as in the SVF of adipose tissue. We show that the expression of INHBB in murine adipose tissue is regulated by changes in obesity and feeding status. We further show that INHBB is regulated by leptin in vivo, and by insulin, LPS and Dex but not leptin in vitro, in differentiated mature 3T3-L1 adipocytes. Taken together, these results suggest that the regulation of INHBB expression in adipose tissue may play a physiological role in the energy balance or the insulin insensitivity associated with obesity.

\section{Declaration of interest}

I declare there is no conflict of interest that could be perceived as prejudicing the impartiality of the research reported.

\section{Funding}

This work was supported by a grant from the Rural and Environment Research and Analysis Directorate of the Scottish Government.

\section{References}

Brown CW, Houston-Hawkins DE, Woodruff TK \& Matzuk MM 2000 Insertion of Inhbb into the Inhba locus rescues the Inhba-null phenotype and reveals new activin functions. Nature Genetics $\mathbf{2 5}$ 453-457.

Cameron VA, Nishimura E, Mathews LS, Lewis KA, Sawchenko PE \& Vale WW 1994 Hybridization histochemical localization of activin receptor subtypes in rat brain, pituitary, ovary, and testis. Endocrinology 134 799-808.

Carlsson LM, Jacobson P, Walley A, Froguel P, Sjostrom L, Svensson PA \& Sjoholm K 2009 ALK7 expression is specific for adipose tissue, reduced in obesity and correlates to factors implicated in metabolic disease. Biochemical and Biophysical Research Communications 382 309-314.

Chang H, Brown CW \& Matzuk MM 2002 Genetic analysis of the mammalian transforming growth factor-beta superfamily. Endocrine Reviews 23 787-823.

Hirai S, Yamanaka M, Kawachi H, Matsui T \& Yano H 2005 Activin A inhibits differentiation of 3T3-L1 preadipocyte. Molecular and Cellular Endocrinology 232 21-26.
Kubota K, Suzuki M, Yamanouchi K, Takahashi M \& Nishihara M 2003 Involvement of activin and inhibin in the regulation of food and water intake in the rat. Journal of Veterinary Medical Science 65 237-242.

Kulkarni RN, Wang ZL, Wang RM, Hurley JD, Smith DM, Ghatei MA, Withers DJ, Gardiner JV, Bailey CJ \& Bloom SR 1997 Leptin rapidly suppresses insulin release from insulinoma cells, rat and human islets and, in vivo, in mice. Journal of Clinical Investigation $\mathbf{1 0 0}$ 2729-2736.

Maeshima A, Miya M, Mishima K, Yamashita S, Kojima I \& Nojima Y 2008 Activin A: autocrine regulator of kidney development and repair. Endocrine Journal 55 1-9.

Meunier H, Rivier C, Evans RM \& Vale W 1988 Gonadal and extragonadal expression of inhibin alpha, beta A, and beta B subunits in various tissues predicts diverse functions. PNAS $\mathbf{8 5}$ 247-251.

Minokoshi Y, Kim YB, Peroni OD, Fryer LG, Muller C, Carling D \& Kahn BB 2002 Leptin stimulates fatty-acid oxidation by activating AMP-activated protein kinase. Nature 415 339-343.

Muttukrishna S, Tannetta D, Groome N \& Sargent I 2004 Activin and follistatin in female reproduction. Molecular and Cellular Endocrinology 225 45-56.

Plotsky PM, Kjaer A, Sutton SW, Sawchenko PE \& Vale W 1991 Central activin administration modulates corticotropin-releasing hormone and adrenocorticotropin secretion. Endocrinology 128 2520-2525.

Rentsch J \& Chiesi M 1996 Regulation of ob gene mRNA levels in cultured adipocytes. FEBS Letters 379 55-59.

Rodgarkia-Dara C, Vejda S, Erlach N, Losert A, Bursch W, Berger W, Schulte-Hermann R \& Grusch M 2006 The activin axis in liver biology and disease. Mutation Research 613 123-137.

Sawchenko PE, Plotsky PM, Pfeiffer SW, Cunningham ET Jr, Vaughan J, Rivier J \& Vale W 1988 Inhibin beta in central neural pathways involved in the control of oxytocin secretion. Nature 334 615-617.

Sjoholm K, Palming J, Lystig TC, Jennische E, Woodruff TK, Carlsson B \& Carlsson LM 2006 The expression of inhibin beta B is high in human adipocytes, reduced by weight loss, and correlates to factors implicated in metabolic disease. Biochemical and Biophysical Research Communications 344 1308-1314.

Thompson TB, Cook RW, Chapman SC, Jardetzky TS \& Woodruff TK 2004 Beta A versus beta B: is it merely a matter of expression? Molecular and Cellular Endocrinology 225 9-17.

Trayhurn P \& Wood IS 2004 Adipokines: inflammation and the pleiotropic role of white adipose tissue. British Journal of Nutrition 92 347-355.

Tsuchida K, Nakatani M, Yamakawa N, Hashimoto O, Hasegawa Y \& Sugino H 2004 Activin isoforms signal through type I receptor serine/threonine kinase ALK7. Molecular and Cellular Endocrinology $22059-65$.

Ueno N, Asakawa A \& Inui A 2007 Blunted metabolic response to fasting in obese mice. Endocrine 32 192-196.

Vejda S, Cranfield M, Peter B, Mellor SL, Groome N, SchulteHermann R \& Rossmanith W 2002 Expression and dimerization of the rat activin subunits betaC and betaE: evidence for the ormation of novel activin dimers. Journal of Molecular Endocrinology 28 137-148.

Werner S \& Alzheimer C 2006 Roles of activin in tissue repair, fibrosis, and inflammatory disease. Cytokine and Growth Factor Reviews 17 $157-171$.

Received in final form 21 May 2009

Accepted 2 June 2009

Made available online as an Accepted Preprint 2 June 2009 